\title{
The snails' tale in deep-sea habitats in the Gulf of Cadiz (NE Atlantic)
}

\author{
L. Génio ${ }^{1, *}$, A. Warén ${ }^{2}$, F. L. Matos ${ }^{1}$, and M. R. Cunha ${ }^{1}$ \\ ${ }^{1}$ Departmento de Biologia \& CESAM, Universidade de Aveiro, Aveiro, Portugal \\ ${ }^{2}$ Department of Invertebrate Zoology, Swedish Museum of Natural History, Stockholm, Sweden \\ *now at: IMAR/DOP-Universidade dos Açores, Horta, Açores, Portugal
}

Correspondence to: L. Génio (luciana.genio@gmail.com)

Received: 11 December 2012 - Published in Biogeosciences Discuss.: 27 February 2013

Revised: 31 May 2013 - Accepted: 25 June 2013 - Published: 30 July 2013

\begin{abstract}
Bridging the Atlantic and Mediterranean continental margins, the South Iberian region has recently been the focus for geological and biological investigations. In this region, the Gulf of Cadiz (GoC) encompasses a great variety of deep-sea habitats that harbour highly diverse biological communities. In this study, we describe the composition of gastropod assemblages obtained from in situ colonization experiments and benthic sampling of deep-sea habitats in the GoC. Gastropod distributional patterns, such as bathymetric ranges, bathymetric turnover, affinity to substrate types and abundance-occupancy relationships, are analysed and interpreted in relation to their inferred dispersal capabilities and substrate availability. Overall, the GoC comprises a high diversity of gastropods (65 species), and distinct assemblages were found in typical sedimentary environments at mud volcanoes and in association with carbonate and coral samples or organic substrata. The number of taxa peaked at the Carbonate Province in the middle slope (600-1200 m depth), a highly heterogeneous area with numerous mud volcanoes, carbonate mounds and corals. Darwin $(1100 \mathrm{~m})$ and Captain Arutyunov $(1300 \mathrm{~m}) \mathrm{mud}$ volcanoes harboured the most species-rich and abundant gastropod assemblages, respectively. Colonization experiments with organic substrata (wood and alfalfa grass) also yielded diverse and abundant gastropod assemblages. These organic inputs allowed the recruitment of local species but mainly of wood specialist taxa that were not previously known from the GoC. Our results suggest that the distribution of gastropod assemblages may be primarily determined by the occurrence of suitable habitats, probably due to the effect of the substrate type on the structural complexity of the habitat
\end{abstract}

and availability and diversity of adequate food sources. The type of larval development is apparently not a limiting factor for colonization of deep-sea habitats. However, the predominance of non-planktotrophy, and especially lecithotrophy, suggests that a trade-off between more limited dispersal capability and higher potential for self-recruitment may be a recurrent pattern in gastropod species inhabiting reducing environments and other patchily distributed deep-sea habitats. A network of suitable habitats that ensures effective population connectivity would explain the predominance and relatively wide distribution of short-distance dispersing non-planktotrophic species in the GoC deep-sea habitats and other geographical regions.

\section{Introduction}

The discovery of highly productive communities at chemosynthetic sites (hydrothermal vents, cold seeps and large organic food falls), and the unsuspected frequency of cold-water coral reefs, completely changed our perception of the deep-sea environment. The combination of geomorphologic, hydrographic, geochemical and biotic features of continental margins generates habitat heterogeneity at spatial scales ranging from centimetres to kilometres, and tens to hundreds of kilometres (Levin and Sibuet, 2012). According to the habitat heterogeneity hypothesis, structurally complex habitats lead to an increase in species diversity by providing a higher number of distinct niche dimensions and diverse ways of exploiting resources (Cordes et al., 2010a). This is the case of the Gulf of Cadiz (GoC) region (NE Atlantic), 
where the interaction of the convergent tectonic setting and complex hydrographical circulation favours the occurrence of a particularly diverse array of deep-sea habitats; these habitats include mud volcanoes, carbonate concretions and cold-water corals that sustain rich biological communities. Gastropods play a relevant role in this vast seepage region; they account for up to $5 \%$ of total macrofaunal abundance in the best-sampled mud volcanoes and rank among the dominant species in the most active ones (Cunha et al., 2013).

Despite the recognized importance of gastropods in deepsea communities, both in terms of diversity and biomass (Levin, 2005; Decker et al., 2011; Bernardino et al., 2012; Ritt et al., 2012), very little is known on their distributional patterns. Gastropods are often highly abundant in reducing environments, but while the gastropod vent fauna is fairly well known, the cold seep taxa are less studied, because seep gastropods are often part of a vast and more diverse surrounding fauna (Sasaki et al., 2010). Gastropod species are also known from organically enriched deep-sea habitats such as sunken wood and animal carcasses (Sasaki et al., 2010), but there is little information on the gastropod fauna associated with cold-water corals and other hard substrate deep-sea habitats (Young, 2009). Gastropods have been often the focus of studies investigating reproduction and dispersal in the deep-sea environment (Rex and Warén, 1982; Bouchet and Warén, 1994; Eckelbarger and Young, 1997; Hodgson et al., 1998; Young et al., 2012). Life-history traits (e.g. egg size, type of larval development, larval feeding behaviour) can be inferred from the larval shell that remains usually well preserved in the adult (Sasaki et al., 2010). A feeding pelagic larval stage (planktotrophic larvae) is frequently assumed to favour widespread geographical distributions, while larval retention would be more compatible with non-planktotrophic species, which develop using a maternal energy source (e.g. lecithotrophic species, brooders, intracapsular development) (Sasaki et al., 2010). However both long-distance dispersal (enabling high rates of habitat occupancy) and self-recruitment owing to local larval retention (enabling high local abundances) are possible in planktotrophic and lecithotrophic dispersers (Shiling and Manahan, 1994; Young, 1999, 2003; Pradillon et al., 2001; Swearer et al., 2002). Yet for brooders, dispersal is often limited by the foraging range of adults. Information on life history traits and dispersal of deep-sea species is vital to understand species distributions and the connectivity of highly patchy or isolated deep-sea habitats.

Samples collected in the GoC during the past decade, encompassing various habitats over a large depth range, complemented by in situ colonization experiments, provided an opportunity to investigate distribution patterns of gastropods and their potential affinity with different substrate types. We compiled information on larval development of each species and inferred their dispersal capabilities. Our working hypothesis is that species distributions are the outcome of the in- teraction of dispersal capability and habitat selection and/or substrate availability.

\section{Material and methods}

This study encompasses a vast seepage area along the Moroccan, Spanish and Portuguese margins of the GoC, at depths between 200 and $4000 \mathrm{~m}$. We consider three sub-regions as described in more detail by Rodrigues et al. (2011): (i) the El Arraiche field (EA) encompasses several mud volcanoes (MVs) in the shallow Moroccan margin (200-600 m) where the proximity to the euphotic zone and to the African coast adds to the great productivity observed in the area; (ii) the Carbonate Province (CP), pierced by several mud volcanoes, corresponds to an extensive bathymetric strip (600$1200 \mathrm{~m}$ ) along the Moroccan and Spanish margins, where the widespread occurrence of authigenic carbonates is accompanied by numerous mounds, thickets and debris of mostly dead cold-water scleractinian corals; (iii) the deep-water field (DF; $1200-4000 \mathrm{~m}$ ), mostly within the Portuguese margin, includes several of the most active mud volcanoes in the region. These sub-regions are characterised by distinct geological, geochemical, and biogenic features. The oceanographic circulation is dominated by the exchanges through the Strait of Gibraltar (Ambar et al., 2002), and by the formation of meddies and recirculation of the Mediterranean Outflow Water (Quentel et al., 2011) that interacts with the seafloor at intermediate depths (mostly coinciding with the CP bathymetric strip). Further details on GoC environmental settings are provided by Cunha et al. (2013) and references therein.

\subsection{Sampling}

Macrofaunal samples were collected in the GoC during 14 cruises carried out between 2000 and 2009 using a variety of quantitative and non-quantitative sampling gears and processed on board accordingly (Rodrigues et al., 2011). The material retained by a $500 \mu \mathrm{m}$ mesh sieve was fixed in 70 or $95 \%$ ethanol for further examination. Overall more than 250 samples were collected from numerous locations, but gastropods were found in 58 samples from 21 locations (Fig. 1). Forty of these samples were collected from typical sedimentary environments at the craters and flanks of the MVs, hereafter referred as "mud volcano" samples, and ascribed to one of the three bathymetric sub-regions (EA: $4 \mathrm{MVs}, 15$ samples; CP: 4 MVs, 7 samples, DF: 5 MVs, 18 samples). Another 18 samples consisted of organic (sunken wood; one sample collected at $2200 \mathrm{~m}$ ) or hard substrata (dead scleractinian coral framework, rocks, carbonate chimneys and carbonate concretions; 17 samples collected at depths between 227 and $1390 \mathrm{~m}$ ) hereafter referred to as "adjacent habitats".

Each sample was ascribed to one of four categories of substrate type: (i) soft (S) - mostly mud breccia from the craters and the flanks of MVs (34 mud volcano samples); (ii) hard 


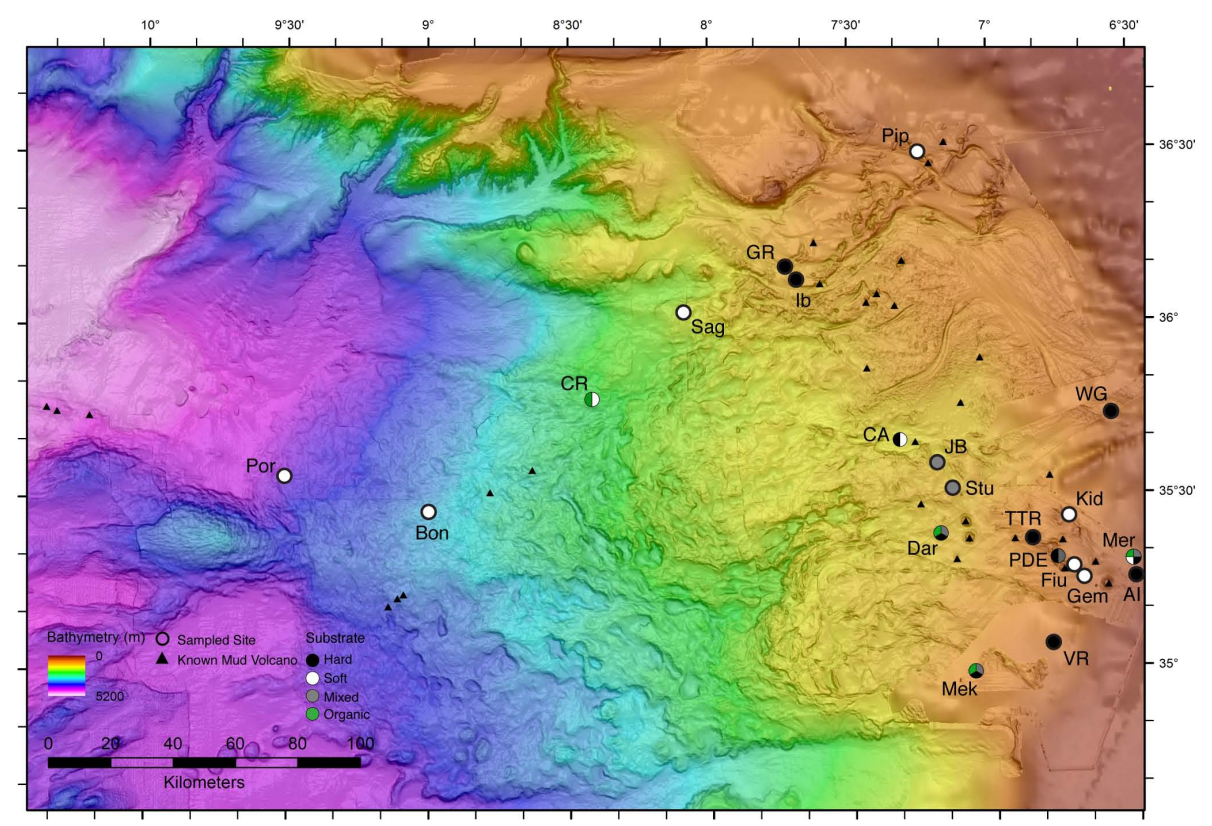

Fig. 1. Map of the study area (Gulf of Cadiz) showing samples locations from $225 \mathrm{~m}$ (AI) to $3900 \mathrm{~m}$ (Por). Multi-coloured circles represent samples from different substrate types. The mud volcanoes are included in three sub-regions: (i) El Arraiche: AI: Al Idrisi*; Fiu: Fiúza MV; Gem: Gemini MV; Kid: Kidd MV; Mer: Mercator MV; (ii) Carbonate Province: Dar: Darwin MV; Ib: Iberico MV*; JB: Jesus Baraza MV; Mek: Meknès* MV; Pip: Pipoca MV; Stu: Student MV; TTR: TTR MV*; and (iii) Deep-water Field: Bon: Bonjardim MV; CA: Captain Arutyunov MV; CR: Carlos Ribeiro MV; Por: Porto MV; Sag: Sagres MV. In the MVs marked with * gastropods were only found in samples from hard substrata in adjacent habitats. The sites GR: Gaudalquivir Ridge; PDE: Pen Duick Escarpment; VR: Vernadsky ridge; WG: West of Gibraltar Strait are sites of accumulation of carbonate chimneys and concretions, and dead scleractinian framework. Colonization experiments were deployed in Mercator, Meknès and Darwin MVs.

(H) - carbonate slabs, crusts, and chimneys, rocks (limestones and other lithologies) and coral framework (16 adjacent habitat samples); (iii) mixed (M) - a mixture of mud breccia, small fragments of carbonate and/or biogenic debris such as coral rubble and shell ash (6 mud volcano and one adjacent habitat samples); and (iv) organic (O) - wood (one sample of sunken wood).

Additional samples were obtained from in situ colonization experiments (CHEMECOLI - CHEMosynthetic Ecosystem COlonization by Larval Invertebrates, (Gaudron et al., 2010) using three types of substrate - wood, dried alfalfa grass and carbonate. The artificial substrates were included inside a Nylon net of $2 \mathrm{~mm}$ mesh, allowing the colonisation of the substrates by metazoan larvae or juveniles but not by the adults of most species. Four sets of experiments were deployed on the craters of Mercator (2 sets), Meknès (1 set) and Darwin (1 set) MVs, and recovered after approx. 1 or 2 yr by using an ROV. After recovery, the different substrates were sub-sampled and processed for different purposes according to a standardised protocol (Gaudron et al., 2010). Two-thirds of each sample were kept for biodiversity studies and fixed in $95 \%$ ethanol (one-third) and formalin (onethird). The whole sub-sample (not sieved) was sorted under a stereomicroscope. Colonization experiments are represented by four samples of wood $(\mathrm{O})$, four samples of alfalfa $(\mathrm{O})$ and four samples of carbonates $(\mathrm{H})$.

The metadata of all samples and their allocation to sample type (mud volcanoes, adjacent habitats, colonization experiments), bathymetric sub-groups of mud volcanoes (EA, CP, $\mathrm{DF})$, and substrate type $(\mathrm{S}, \mathrm{M}, \mathrm{H}, \mathrm{O})$ are provided in Supplement Table 1.

\subsection{Taxonomic identifications and data analyses}

Gastropod specimens were identified to species level whenever possible. Several taxa were not yet matched with a species name but they were all sorted into putative species and ascribed a codename consistent throughout the samples. Therefore the estimated species richness can be considered accurate, although minor changes may be made in the future following more thorough taxonomic revisions of the material. This is the case of the specimens ascribed to the family Marginellidae, and genera Coccopygia and Copulabyssia, which may include more than one species. Species identifications were based on morphological observations of shells, radula and opercula using optical and scanning electron microscopy and critical point dried soft parts. Specimens were treated according to the methods described in Geiger et al. (2007). In many cases, species identification also requires 
DNA sequence analyses, which is currently in progress. Taxonomical considerations and descriptions of new taxa are in preparation and will be published elsewhere.

Our dataset was obtained from a wide variety of sampling gear; it is very heterogeneous and in many cases abundances are not referable to a given sampling area, although we used standardized procedures for each type of sampling gear. Therefore, density estimates were only possible for a limited number of samples taken with USNEL boxcores (area: $0.25 \mathrm{~m}^{2}$ ) (Cunha et al., 2013).

The bathymetric range of each species in the region was assessed based on presence/absence data obtained from the total set of samples (mud, volcanoes, adjacent habitats and colonization experiments). Species bathymetric ranges were then used to draw accumulation, loss and turnover curves representing taxa replacement with increasing depth (Ugland et al., 2003; Colwell et al., 2004). The analysis of abundanceoccupancy relationships was approached by classifying each taxon into one of five distributional categories: (i) singletons - corresponding to single occurrences, (ii) rare species - two or three individuals found at one substrate type, (iii) moderate - more than three and less than 10 individuals found in one or more substrate types, (iv) abundant - taxa with more than 10 individuals found in two substrate types, and (v) ubiquitous - taxa found at all three substrata (usually also very abundant).

Finally, abundance-occupancy patterns were compared in relation to the following developmental categories: planktotrophic, non-planktotrophic and lecithotrophic. Wherever possible, the development mode of each species was obtained from available data in the literature (Supplement Table 2), or inferred from protoconch morphology using the "Thorson's apex theory" (Jablonsky and Lutz, 1983) and comparisons to closely related taxa with known development mode. We consider that planktotrophic larvae have an obligate feeding pelagic stage, while non-planktotrophs develop using a maternal energy source. Non-planktotrophic development includes life cycles with a non-feeding pelagic phase (herein designated loosely as lecithotrophic), brooders and intra-capsular development. In some cases, information compiled in the literature allowed for the assignment of species to the non-planktotrophic sub-category of "lecithotrophs" (Supplement Table 2).

\section{Results}

Gastropods occurred in approximately one fifth of the macrofaunal samples collected in the mud volcanoes and adjacent habitats of the GoC. A total of 2362 gastropod specimens were examined and ascribed to 65 taxa (Fig. 2; Supplementary Table 2). Caenogastropoda is the most diverse subclass ( 27 species in 15 families), followed by the Vetigastropoda (24 species in 11 families) and the Heterobranchia ( 9 species in 3 families). Less diverse were the Cocculini- formia with three species all belonging to the family Cocculinidae, including one new genus that waits formal description and the Patellogastropoda and Neomphalina represented by only one species each. A high proportion (35\%) of taxa were singletons, and more than half $(63 \%)$ of the species was recorded in just one or two samples.

\subsection{Species distributions}

The most striking feature of the observed bathymetric distribution of gastropods (Fig. 2) is the high number of species with overlapping distributions at the middle slope (roughly $500-1500 \mathrm{~m}$ ) contrasting with the scarce number of species at greater depths (down to $4000 \mathrm{~m}$ ). Carbonate concretions and scleractinian corals rarely occur deeper than $1200 \mathrm{~m}$ and mud volcanoes are more sparsely distributed in the deep field, thus gastropods were only found in five sites across this large bathymetric range. The accumulation, loss and turnover curves (Fig. 3) reflect the scarcity of gastropod occurrences at great depths and highlight the three major locations of species replacement: Mercator MV (EA) (18 species added and 8 lost), Darwin MV where more species are lost than gained (13 lost and 10 gained, respectively), and Captain Arutyunov MV where ten species from the shallower areas have their deepest limit, and first occurrence was recorded for six taxa.

The taxonomic composition of gastropod assemblages shows a distinct variation according to the substrate type (Fig. 4a; all samples except colonization experiments). The number of Vetigastropoda and Heterobranchia taxa showed little variation (7-9 and $2-5$ species, respectively) among hard, soft and mixed substrata. On the other hand, the Caenogatropoda were represented by a much higher number of taxa in soft sediments (19 in opposition to 8 and 10 , respectively in "mixed" and "hard"), and clearly dominated the assemblage of this sedimentary substrate type. Mixed sediments showed the most even distribution of the different major taxonomic groups (Fig. 4a) and were the only substrate where Patellogastropoda and Neomphalina occurred. The only sample representing organic substrate (a small wood fall collected at Carlos Ribeiro MV) yielded only three species from which two were Cocculiniformia (Cocculinidae n. gen. and Fedikovella sp.), a group that was never found in the other substrata. The number of species occurring exclusively in soft sediments was higher (22 out of 32) than the one observed exclusively on hard substrata (12 out of 21). All three species in organic substrate occurred only in that sample, while the remaining 22 taxa were found either in mixed substrate or in more than one type of substrate (7 and 15 species, respectively).

A total of 21 taxa were found in the 17 hard substrate samples (Fig. 4a) from adjacent habitats located along the upper slope of the Moroccan and Spanish margins, usually in the vicinity of MVs, but with little or no influence of the cold seeps (Supplement Table 1). The highest number of 


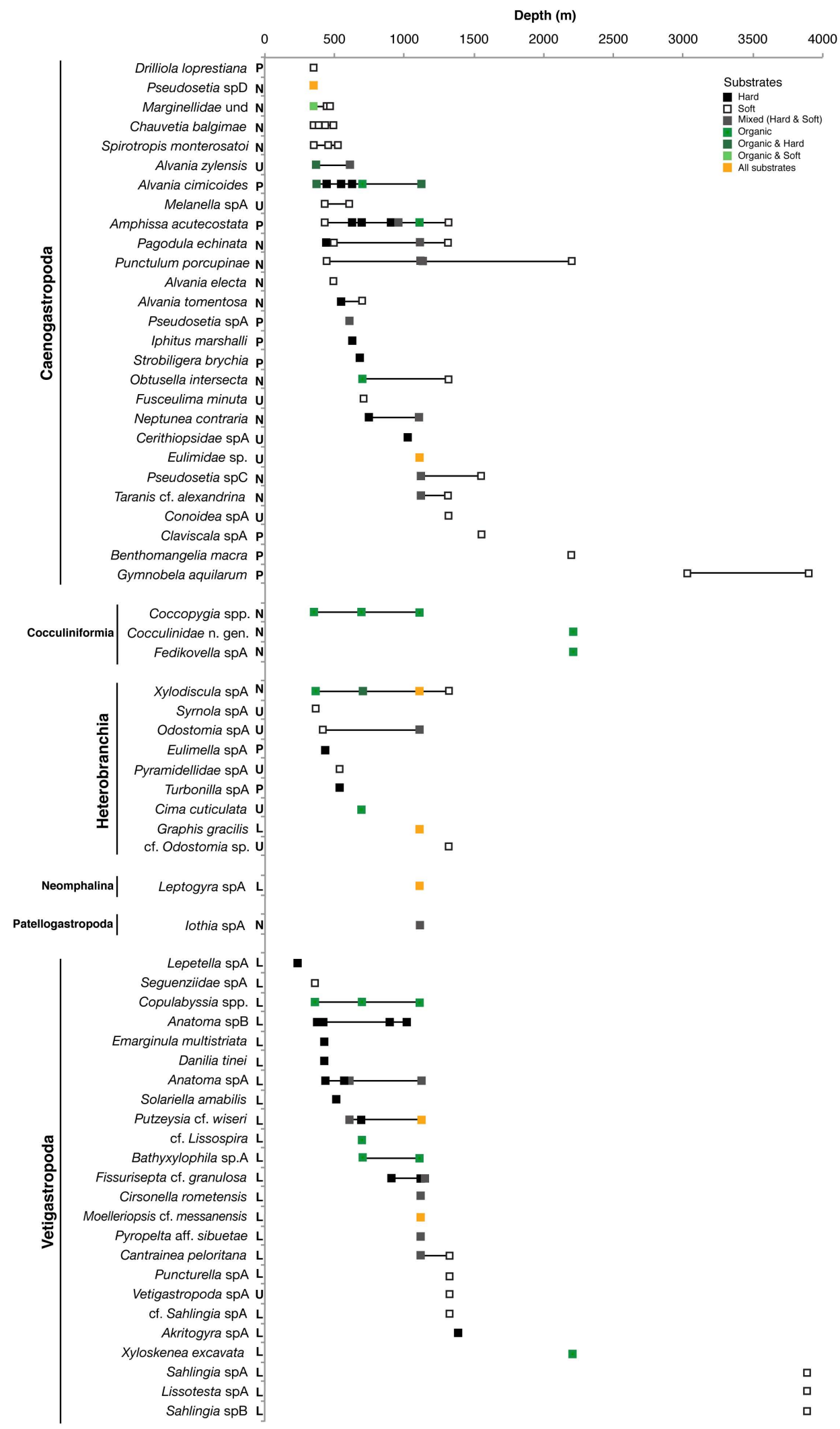

Fig. 2. Bathymetric distribution of the gastropod taxa collected in the Gulf of Cadiz. Type of larval development is indicated after each taxon's name. P: planktotrophic; L: lecithotrophic; N: non-planktotrophic; U: unknown. Data from all samples and experiments are included. 


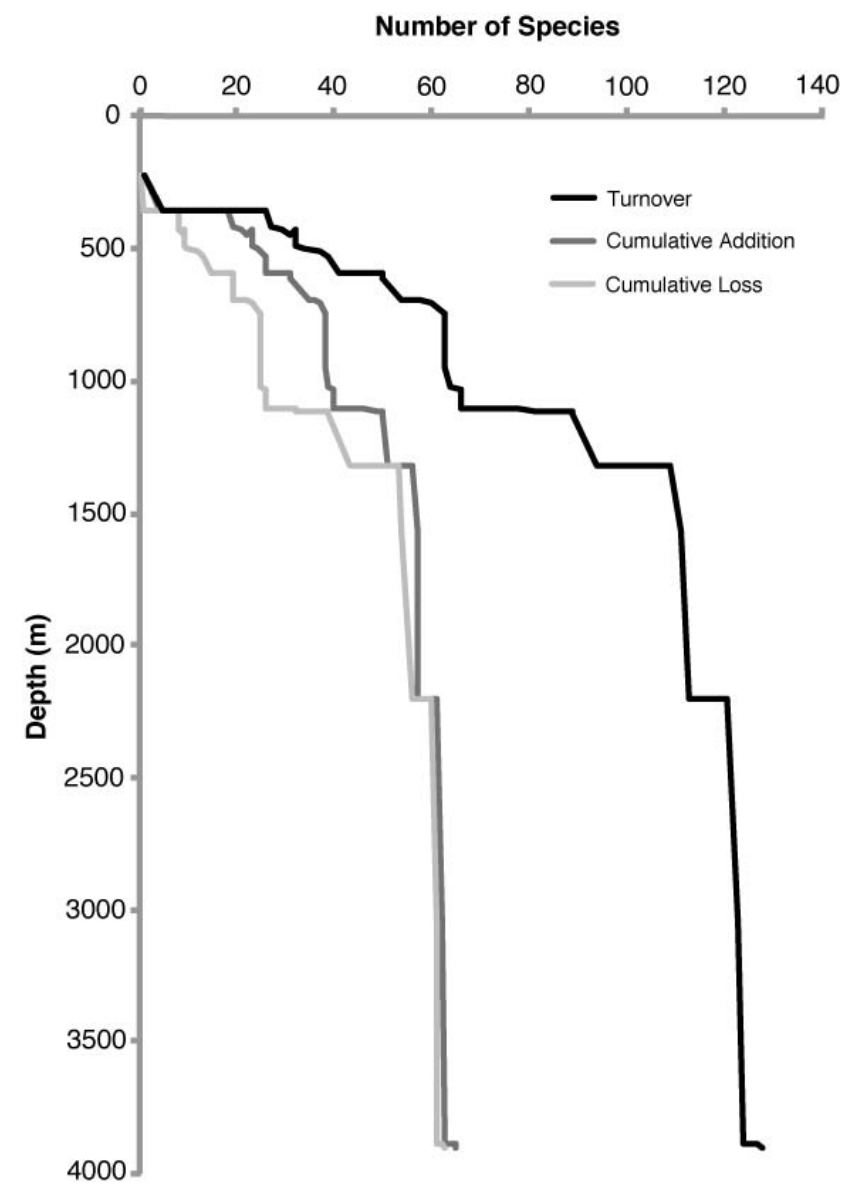

Fig. 3. Regional accumulation, loss and turnover of gastropod taxa along the depth gradient in the Gulf of Cadiz. Data from all samples and experiments are included.

samples (5) was collected in the Pen Duick Escarpment (Moroccan upper slope). Very low numbers of individuals were obtained from these habitats, and the majority of species were singletons. The Caenogastropoda Alvania cimicoides (6 individuals) and Alvania zylensis (5), and the Vetigastropoda Putzeysia wiseri (6) and Anatoma $\mathrm{spB}(6)$ were the most common species in hard substrata, but the two Caenogastropoda were restricted to shallower depths.

Mud volcano samples consisted of mixed (6 samples) and soft sediments (34 samples). In fact, the mud volcanoes were the main sampling target of this study and their gastropod assemblages were the best characterized, with a total of 42 species collected (Fig. $4 \mathrm{~b}$ - mud volcano samples only). From these, 14 species were present in EA (4 MVs; 15 samples), 20 in CP (4 MVs; 7 samples) and 19 in DF (5MVs; 18 samples) and only eight species were shared between different bathymetric sub-regions. Vetigastropoda were poorly represented in the shallower mud volcanoes (EA: 1 species) that were clearly dominated by Caenogastropods (10 species; $70 \%$ of the total species richness, Fig. 4b). In the deeper mud volcano sub-regions ( $\mathrm{CP}$ and $\mathrm{DF}$ ) the contribution of Caenogastropoda and Vetigastropoda was more balanced, but the highest diversity at the sub-class level (also at species level) was observed in the group of mud volcanoes from the Carbonate Province (Fig. 4b).

Three Caenogastropod species showed a wide bathymetric range and were found across the three sub-regions, Punctulum porcupinae (5 samples), Pagodula echinata (10 samples) and Amphissa acutecostata (11 samples). The major contributors to the species richness in each region were the assemblages from Mercator (EA, 350 m), Darwin (CP, 1100 m) and Captain Arutyunov MVs (DF, $1300 \mathrm{~m}$ ) with 8, 17 and 11 species represented in 8,4 and 11 samples, respectively. Marginellidae were always abundant (up to 192 ind. $\mathrm{m}^{-2}$ ) in the crater of Mercator, accounting up to $4.9 \%$ of the total macrofaunal abundance (Cunha et al., 2013). The crater of Darwin MV is covered with large authigenic carbonate slabs and therefore quantitative sample are not available for estimates of abundance. However the neomphalin Leptogyra spA was the most abundant gastropod collected using a suction sampler in mytilid beds from this MV - this gastropod occurred exclusively in this MV. In sediment samples containing gas hydrates from the crater of Captain Arutyunov $\mathrm{MV}$, gastropods reached 600 ind. $\mathrm{m}^{-2}-$ an undetermined vetigastropod (Vetigastropoda spA), the rissoid Obtusella intersecta and the xylodisculid Xylodiscula spA were the fourth, fifth and sixth most dominant species of the macrofaunal assemblage (5.7, 4.9 and $2.9 \%$ of the total macrofaunal abundance, respectively; Cunha et al., 2013).

\subsection{Colonization of artificial substrata}

CHEMECOLI experiments were densely colonised by gastropods, in particular the wood substrate and the alfalfa grass deployed in Meknès and Darwin. Overall, the colonization experiments showed high diversity at the major taxonomic level (Fig. 4c). Colonization of the carbonate substrata was generally scarce, and only a few gastropod species (9 in total) were collected from the experiments deployed in Mercator (Pseudosetia spD, 26 specimens), Meknès (Xylodiscula spA, one individual) and Darwin (seven taxa, 15 individuals). The eight samples of experimental organic substrates yielded a total of 17 taxa (Fig. 4c). Pseudococculinids were by large the dominant taxa - Copulabyssia spp. was the most abundant taxa especially in Meknès and Darwin with over 1200 individuals collected, followed by the cocculinid Coccopygia spp. with a couple of hundred individuals. Much lower numbers (21 Copulabyssia spp. and 3 Coccopygia spp.) were also collected in Mercator. These species had never been found in typical mud volcano settings in the GoC. Colonization experiments showed that several species (12) occurring in the mud volcanoes can also explore opportunistically organic substrata. These include abundant species such as Xylodiscula spA (Mercator, Meknès and Darwin MVs), Marginellidae and Pseudosetia spD (Mercator MV), and Leptogyra spA 

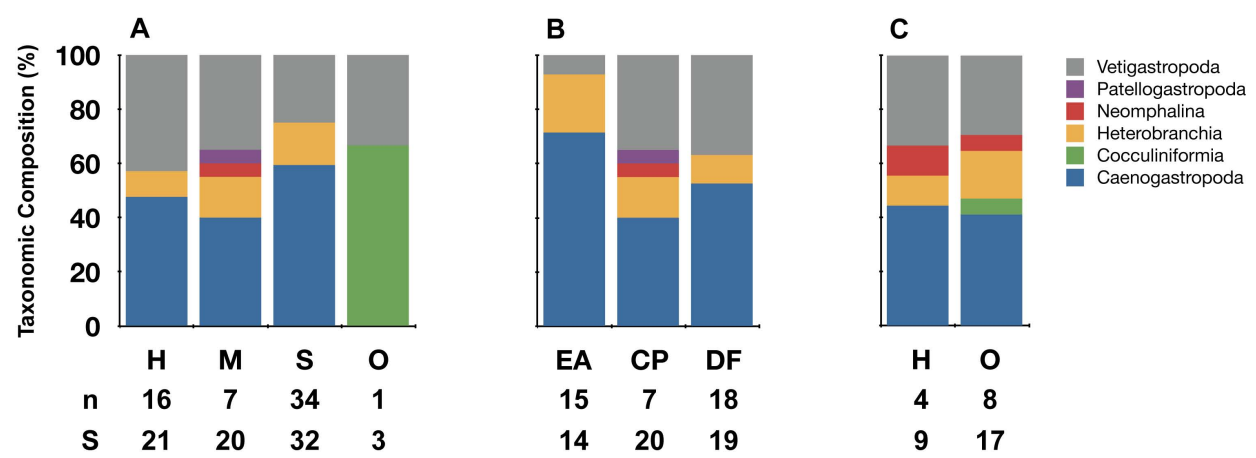

Fig. 4. Taxonomic composition of gastropod assemblages in the Gulf of Cadiz. (A) Comparison between different substrate types (samples from mud volcano and adjacent habitats). (B) Comparison between bathymetric sub-regions (samples from mud volcanoes only). (C) Comparison between hard and organic artificial substrata from in situ colonization experiments. Figures below bars indicate the number of samples $(n)$ and the number of species (S) in each assemblage. H: hard; M: mixed; S: soft; O: organic; EA: El-Arraiche; CP: Carbonate Province; DF: deep field.

(Darwin MV). Interestingly the rissoid Alvania cimicoides, found in carbonate and coral sites at Pen Duick Escarpment (in the vicinity of EA MVs), was also able to colonize wood and dried alfalfa grass not only in Mercator but also at the deeper Meknès and Darwin MVs. Obtusella intersecta, on the other hand, occurs in the crater of Capt. Arutyunov MV $(1300 \mathrm{~m})$ and was able to colonise dried alfalfa grass in the shallower Meknès MV $(350 \mathrm{~m})$.

\subsection{Larval development}

From the 65 gastropod species found in the GoC deep-sea habitats and experimental settings, 25 are lecithotrophs, another 17 species were considered as non-planktotrophic and only 11 species have larval shells typical of planktotrophic development. For the remaining 12 species, the type of larval development is unknown and could not be inferred from the available specimens (Fig. 2 and Supplement Table 2). Nonplanktotrophic species presumably have the lowest dispersal capability, but yet showed to have abundance-occupancy patterns categorised mostly as Ubiquitous or Abundant (occurring usually in more than one substrate and in relatively high numbers) with only about $30 \%$ classified as Singleton and Rare (Fig. 5). Planktotrophic species, on the other hand, have pelagic-feeding larval phases that are likely to result in greater transport distances. However, $82 \%$ of the gastropod species with this type of development showed restricted distributions and occurred mostly in one type of substrate only as Singleton and Rare taxa $(55 \%$ and $27 \%$, respectively). Because lecithotrophic species have non-feeding pelagic larvae, their dispersal ability is assumed to be intermediate in relation to the other development modes; these species showed in fact a more even contribution of Singleton and Moderate categories ( $40 \%$ and $36 \%$, respectively).

Our results do not show a relationship between large distributional range and planktotrophic development. The three species exhibiting wider bathymetric ranges (present in all mud volcano sub-regions) have distinct modes of larval development - Amphissa acutecostata is planktotrophic, while Pagodula echinata and Punctulum porcupinae have non-planktotrophic larvae. From the four species with distribution spanning the two deeper sub-regions (CP and DF), one is categorised as lecithotrophic and three are nonplanktotrophic. Planktotrophs recorded in our samples are typically caenogastropods, occurring in hard substrata from adjacent habitats, at depths shallower than $1200 \mathrm{~m}$. In fact, most of the species occurring in high numbers, with wide bathymetric ranges or in various substrate types are nonplanktotrophic.

\section{Discussion}

\subsection{Abundance and distribution}

This study provides the first report on the gastropod assemblages from mud volcanoes and adjacent deep-sea habitats in the GoC. By using in many cases a $500 \mu \mathrm{m}$ sieve we may have underestimated the species richness and abundances, as most deep-sea gastropods have minute sizes (Geiger et al., 2007). Considerably higher abundances have been recovered from cold seep sites using $250 \mu \mathrm{m}$ sieves (Decker et al., 2011; Ritt et al., 2012). Nevertheless, gastropods showed diverse assemblages in the GoC and, although practically absent in reference samples (hemipelagic sediments in the vicinity of mud volcanoes), they were among the dominant species in samples from Mercator, Darwin and Capt. Arutyunov MVs; these MVs are thought to be the most active respectively in the EA, CP and DF sub-regions considered in this study. Active gas bubbling was observed both in Mercator and Darwin (Vanreusel et al., 2009) and gas hydrates occur in the near surface at Capt. Arutyunov (Cunha et al., 2013). Gastropods are often found among the dominant taxa in several 

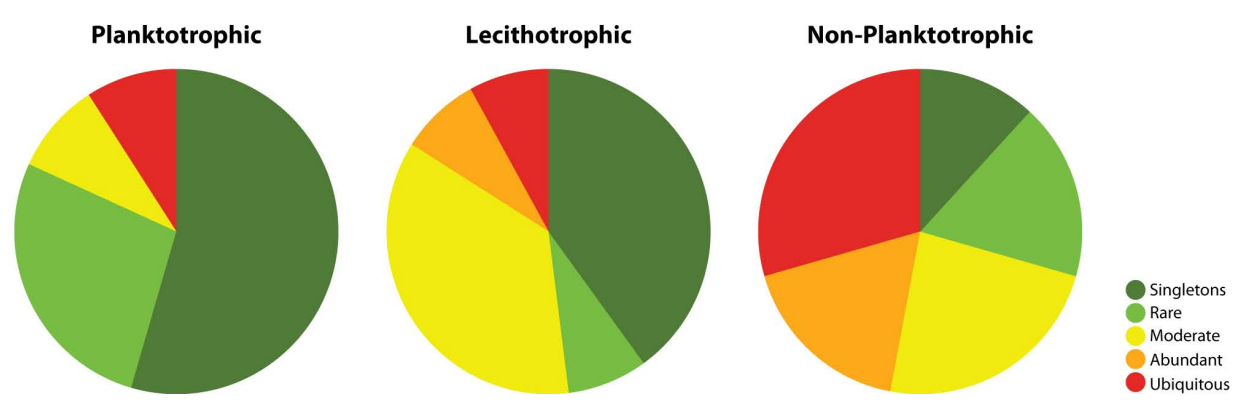

Fig. 5. Distributional patterns of Gulf of Cadiz deep-sea gastropod taxa with distinct larval development types. See text and Supplementary Table 2 for explanation of distributional categories and larval development data.

cold seeps (Levin, 2005 and references therein), but the highest abundances (over 30000 ind. $\mathrm{m}^{-2}$ ) were reported from frenulate habitats in the Håkon Mosby MV and Nyegga "pingoes" (Norwegian Margin; Decker et al., 2011). Decker et al. (2011) suggested that the presence of the high densities of gastropods is explained by geochemical conditions rather than by the presence of tubeworms. However, Govenar and Fisher (2007) found that the physical structure provided by the tubeworms may be particularly important for the attendant epifauna in areas of high and intermediate fluid flow (more than in low-flow regions).

Gastropod densities are much more modest in the $\mathrm{GoC}$ (up to 600 ind. $\mathrm{m}^{-2}$ ) than in the Håkon Mosby MV but, on the other hand, species richness is among the highest reported from cold seeps. In the GoC a total pool of 42 species were collected from mud breccia and mixed sediments in the MVs' craters; 17 species were recorded in Darwin MV alone, which is more than the total of 11 species reported for the Anaximander and Olimpi regions in the E Mediterranean (ca. 1700-2000 m water depth; Olu-Le Roy et al., 2004). Other studies with species level resolution mention even lower gastropod species richness: five species in the Marmara Sea (Ritt et al., 2012), five species in the Barbados (1000-2000 m, Olu et al., 1997), and eight species in tubeworm and mussel habitats in the Gulf of Mexico (1000-2750 m; Cordes et al., 2010b).

There is a high similarity at genus and even at species level between the gastropod fauna in the seeps of the E Mediterranean (Olu-Le Roy et al., 2004), Marmara Sea (Ritt et al., 2012) and GoC (this study). The trochid species Putzeysia wiseri appears to be particularly common across these three geographical regions, often associated with carbonates or mixed substrata. Like the majority of gastropod species found in seeps and vents, $P$. wiseri is a presumed grazer that explores opportunistically the increased bacterial biomass. About half of the genera recorded in the GoC ( 26 out of 48) are also known from other reducing habitats (vent, seep and organic falls; review by Sasaki et al., 2010; Decker et al., 2011; Ritt et al., 2012). In fact, the fauna from cold seeps shares many commonalities with other deep-sea environments characterized by sulphidic, low-oxygen, or disturbed sediments, and there are some cases of confirmed overlap in the distribution of heterotrophic species (Levin et al., 2009; Bernardino et al., 2010, 2012).

Apparently many gastropod species in the GoC occurred exclusively in one type of substrate $(\mathrm{H}, \mathrm{M}, \mathrm{S}, \mathrm{O})$ but this analysis is confounded by the very high percentage of singletons. If we remove single occurrences the number of species found exclusively in one substrate type is similar to the number of species occurring in two or more substrata. Moreover, the colonization experiments showed that several gastropods (12 species) occurring in the MV sediments and hard substrata were also able to recruit on organic substrata; these are mainly bacterial grazers and a few predators that may thrive in these trophically enhanced assemblages.

\subsection{Species replacement with depth}

The patterns of species replacement with depth in the North Atlantic are well documented for several taxa; in general the shelf-slope break shows the most pronounced transition in species composition. A more continuous but high rate of replacement is observed at bathyal depths, and lessens at abyssal depths (Rex, 1981). Regions of conspicuous faunal change have been explained by: (i) temperature mean and variation; (ii) differential adaptation to hydrostatic pressure; (iii) topography; (iv) effects of sedimentary pattern and substrate type on food sources; and (v) the effects of deep boundary currents on larval dispersal (Rex, 1981).

Regional oceanographic circulation is an important point to be taken into account. In the $\mathrm{GoC}$, the influence of the Mediterranean Outflow Water in particular, may be pertinent for explaining the highest species turnover observed at $1100-1300 \mathrm{~m}$ which coincides roughly to the deeper limit of this water mass. The formation of typical meddies (Quentel et al., 2011) may indeed act as a retention mechanism and/or hinder vertical movements of larvae.

For our dataset, the pattern of substrate types (point iv) also seems to be of particular relevance. High rates of change in the gastropod assemblages occur at the most active MVs and may be related to the increased availability of food sources for grazers (microrganisms, detritus). A higher 
trophic diversity can also be sustained by these productive ecosystems: some species are commensals or parasitic on polychaetes (e.g. Odostomia spp., Eulimella spp.; Sasaki et al., 2010) or on echinoderms (e.g. Eulimidae; Sasaki et al., 2010) and large buccinid carnivores are often seen actively foraging at the craters of mud volcanoes (e.g. Neptunea contraria at Meknès MV and an undetermined species at Capt. Arutyunov MV; M. R. Cunha, personal observation, 2006).

Moreover, the highest overlap of species distributions is observed at the depth range between 500 and $1500 \mathrm{~m}$, coinciding with the increased habitat heterogeneity promoted by the widespread occurrence not only of mud volcanoes, but also of carbonate concretions, carbonate chimneys and scleractinian coral framework and rubble. The perception of structurally complex habitats with distinct niche dimensions is dependent on the size, mobility and dispersal capability of the organisms enabling diverse ways of exploiting resources, and therefore promoting higher biodiversity (Cordes et al., 2010a). According to Etter et al. (2005) the bathyal zone may play an important role in generating deep-sea biodiversity because the strong gradients and great biotic and abiotic heterogeneity at these depths might impose different selective regimes that increase the probability of population differentiation and speciation. In fact, the potential for gastropod radiation within the deep-sea is highest in the upper bathyal region (Etter and Rex, 1990).

\subsection{Developmental modes and dispersal}

The artificial substrata deployed for colonization experiments (CHEMECOLI) proved to be very efficient in the collection of all range of individual sizes, from recruitment to reproductive maturity, including a high number of recently settled juvenile stages. CHEMECOLI deployments in the GoC retrieved a higher number of gastropod species than similar experiments in the Håkon Mosby MV (1257 m) and the cold seeps at Nile Deep Sea Fan (1693 m) (Gaudron et al., 2010). Regardless of the differences in sample processing, artificial organic falls yielded high abundances of gastropod species (up to 281 ind per $\mathrm{dm}^{3}$ of initially deployed substrate) compared to the numbers obtained in the background mud volcano sediments. These organic inputs not only allowed proliferation of species already occurring in their vicinity (e.g. Pseudosetia $\mathrm{spD}$ and Xylodiscula $\mathrm{spA}$ ), but also favoured the recruitment of species only known from relatively distant MVs (e.g. A. cimicoides and $O$. intersecta), and particularly wood specialist taxa (Cocculinidae, Copulabyssia, Xyloskenea, Bathyxylophila and cf. Lissospira) that were not found in the other GoC deep-sea habitats. Larval development is known for 17 of the 20 species collected in these organic substrates, and only two species are planktotrophic.

Remarkably, most of the taxa developing through an obligate feeding pelagic phase were rare in the mud volcano sediments. In contrast, the predominance of nonplanktotrophic species and their observed abundance- occupancy patterns (mostly Ubiquitous and Abundant) suggest that short distance dispersal, resulting in high selfrecruitment, may be favoured at ephemeral, sparsely distributed reducing habitats. As many propagules show a negative exponential survival with distance from the parent, an elevated colonisation rate would be anticipated with proximity to the larval pool, i.e. the parental habitat (MacArthur and Wilson, 1967). In this way, the risk of settling in an unsuitable habitat is also considerably reduced.

Planktotrophic larvae, transported over large distances by ocean currents, are assumed to allow wider geographical distributions and low genetic differentiation of populations. But a long pelagic duration (planktotrophic) may lead to extremely low propagule concentrations and therefore low levels of recruitment, which agrees with the observed abundance-occupancy patterns (mostly Rare and Singleton). On the other hand, non-planktotrophic development is often associated with narrow distributions and high levels of endemism (Castelin et al., 2011). These assumptions have proven to be unrealistic for species colonizing deep-sea chemosynthetic habitats as shown also by the abundance occupancy relationships observed in our study. Several examples are found in the literature that showed no noticeable difference in distribution between species with planktotrophic larvae, non-feeding dispersal phase or those that crawl directly out of an egg-capsule (Sasaki et al., 2010). Although the type of larval development is not a limiting factor for the dispersal of deep-sea gastropods, our results show a preponderance of non-planktotrophic and especially lecithotrophic over planktotrophic development in the gastropod species inhabiting the studied deep-sea habitats. A remarkable discovery of a new development mode of Provannid gastropods (the Waren's larvae) called attention to how much is yet unknown regarding life histories in the deep-sea, and also challenged the assumption of phylogenetic conservative reproduction and development modes (Reynolds et al., 2010).

Among the gastropod taxa found in the GoC, three species are also found in the eastern Mediterranean cold seeps, but only Benthomangelia macra is known to have planktotrophic development. The present knowledge of oceanographic circulation indicates that planktonic larvae can be transported into the Mediterranean from the Atlantic by inflowing surface currents, while Mediterranean Outflow water would only allow transport in the opposite direction at $50-300 \mathrm{~m}$ depth (Quentel et al., 2011). Mediterranean bottom waters may hinder the successful establishment of species (at the time of metamorphosis or at the time of reproduction) due to its hydrographical characteristics, including high temperature and high salinity. This led Bouchet and Taviani (1992) to postulate that Mediterranean deep-sea fauna represents reproductive sterile pseudopopulations that are constantly dependent on pelagic larval inflow from Atlantic source populations. To understand the consequences of different larval development modes that affect population connectivity, divergence time among populations and changes in effective 
population sizes must also be considered (Hart and Marko, 2010). Larval dispersal potential and connectivity between populations of marine invertebrates are highly affected by local hydrodynamics that can create significant variability in gene flow and recruitment at different temporal and spatial scales (Bell, 2008).

Colonization of patchy habitats, such as wood and bones, by non-planktotrophic larvae, with putative limited dispersal ability, is yet rather intriguing. Relying on dispersal by crawling adults does not seem to explain colonization of organic falls and other reducing habitats, often separated by hundreds or thousands of kilometres. Other authors suggested an alternative dispersal option by rafting (Sasaki et al., 2010), where individuals could stay afloat and drift a long distance attached to gliding objects (e.g. small wood chips). Despite the prominence of developmental modes in the debate of deepsea species dispersal, other reproductive traits may be of utmost importance. Foggo et al. (2007) highlight the role of fecundity in determining propagule pressure and consequently dispersal probability in many marine macroinvertebrates.

A possible explanation for widely distributed nonplanktotrophic species in deep-sea habitats would be the socalled stepping-stone hypothesis, which relies on the colonization of additional intermediate sites found between distant seeps and/or sunken wood and bones. Considering the size-scale of deep-sea gastropods, and their primary feeding habits (bacterial grazing and detritus feeding), additional habitats may in fact be very frequent. As demonstrated by our colonization experiments gastropod species that are common in the mud volcanoes are also able to colonize organic falls. Also, some of the species that colonised these organic substrata were previously known only from relatively distant location in the GoC (i.e. they were not known to occur in the local background fauna). The possibility of connectedness of adequate habitats for deep-sea gastropods is therefore not difficult to envisage; this would allow survival and reproduction of individuals and the persistence of populations. The large number of singletons in our samples may indicate low propagule pressure and/or recruitment success, but it also suggests species distributions are still poorly known and that the $\mathrm{GoC}$ deep-sea gastropod fauna may be even more diverse than reported here. Moreover, because our sampling effort was focused on mud volcanoes, the occurrence of more frequent small effective populations cannot be discarded; these can serve as larval sources for colonization of highly productive but patchily distributed habitats, such as phytodetritus, wood and bone falls and sites with various seepage regimes.

\section{Concluding remarks}

It is expected from the GoC biogeographical context that its deep-sea gastropod fauna includes species from Atlantic and Mediterranean areas. Our study confirms this premise and gives new evidence for connectivity of deep-sea gastropod communities inhabiting reducing environments. Our results also support the hypothesis that the highest biodiversity of gastropods at the upper bathyal region is related to the strong gradients and habitat heterogeneity at these depths. Different substrate types, in particular, are determinant for the structural complexity of the habitat and/or availability of food sources and are successfully colonized by gastropods with different larval development modes and feeding types. Moreover, our work suggests that various deep-sea habitats form a network of suitable environments, which enhances diversity and ensures connectivity of deep-sea gastropod populations. Future research should focus on species-level taxonomy, population dynamics and genetic structure. Mapping of deep-sea habitats and a better knowledge of local and regional hydrography are also of utmost importance in order to better understand current species distributions and potential population connectivity across ocean basins.

\section{Supplementary material related to this article is available online at: http://www.biogeosciences.net/10/ 5159/2013/bg-10-5159-2013-supplement.pdf.}

Acknowledgements. We are grateful to the chief scientists, scientific teams, ROV technical teams, captains and crews of the oceanographic cruises that collected samples for this work: TTR10 to TTR17, MSM01/03, 64PE237, 64PE253, 64PE284, JC10 and B09/14, and to Clara F. Rodrigues (CESAM) for her invaluable help with sample sorting. The lead author wishes to acknowledge Ana Hilário (CESAM) for the supportive discussions during the course of this work. This project (SE-TAF-1543) received support from SYNTHESYS (http://www.synthesys.info/), which is financed by the European Community - Research Infrastructure Action under the FP7 "Capacities" Specific Programme. This research was partially supported by the HERMES project, EC contract GOCE-CT_2005-511234, funded by the European Comission's Sixth Framework Programme under the priority "Sustainable Development, Global Change and Ecosystems", and is a contribution to HERMIONE project, Grant Agreement no. 226354 funded by the European Community's Seventh Framework Programme (FP7/2007-2013) and by the CHEMECO ESF EURODEEP project (FCT; EURODEEP/0001/2007). The lead author was funded by a post-doctoral fellowship (SFRH/BPD/51858/2012) from the Portuguese National Science Foundation (FCT), and FLM was supported by a CHEMECO project grant (BI/UI88/4610/2011). Finally, we acknowledge the two anonymous reviewers who contributed to improve significantly our first version of this paper.

Edited by: P. Weaver 


\section{References}

Ambar, I., Serra, N., Brogueira, M. J., Cabeçadas, G., Abrantes, F., Freitas, P., Gonçalves, C., and Gonzalez, N.: Physical, chemical and sedimentological aspects of the Mediterranean Outflow off Iberia, Deep-Sea Res. Pt. II, 49, 4163-4177, 2002.

Bell, J. J.: Connectivity between island Marine Protected Areas and the mainland, Biol. Conserv., 141, 2807-2820, 2008

Bernardino, A. F., Smith, C. R., Baco, A., Altamira, I., and Sumida, P. Y. G.: Macrofaunal succession in sediments around kelp and wood falls in the deep NE Pacific and community overlap with other reducing habitats, Deep-Sea Res. Pt. I, 57, 708-723, 2010.

Bernardino, A., Levin, L., Thurber, A., and Smith, C.: Comparative composition diversity and trophic ecology of sediment macrofauna at vents seeps and organic falls, Plos One, 7, e33515, doi:10.1371/journal.pone.0033515, 2012.

Bouchet, P. and Taviani, M.: The Mediterranean deep-sea fauna: pseudopopulations of Atlantic species?, Deep Sea Res. Pt. A., 39, 169-184, 1992.

Bouchet, P. and Warén, A.: Ontogenetic migration and dispersal of deep-sea gastropoda larvae, in: Reproduction, larval biology, and recruitment of the deep-sea benthos, edited by: Young, C. M. and Eckelbarger, K. J., Columbia University Press, New York, 98117, 1994.

Castelin, M., Puillandre, N., Lozouet, P., Sysoev, A., Forges, B., and Samadi, S.: Molluskan species richness and endemism on New Caledonian seamounts: Are they enhanced compared to adjacent slopes?, Deep-Sea Res. Pt I, 58, 637-646, 2011.

Colwell, R. K., Mao, C. X., and Chang, J.: Interpolationg, Extrapolating, and comparing incidence-based species accumulation curves, Ecology, 85, 2717-2727, 2004.

Cordes, E. E., Cunha, M. R., Galeron, J., Mora, C., Olu-Le Roy, K., Sibuet, M., Van Gaever, S., Vanreusel, A., and Levin, L. A.: The influence of geological, geochemical, and biogenic habitat heterogeneity on seep biodiversity, Mar. Ecol.-Evol. Persp., 31, 51-65, 2010a.

Cordes, E. E., Hourdez, S., and Roberts, H. H.: Unusual habitats and organisms associated with the cold seeps of the Gulf of Mexico, Topics in Geobiology, 33, 315-331, 2010b.

Cunha, M. R., Rodrigues, C. F., Génio, L., Hilário, A., Ravara, A., and Pfannkuche, O.: Macrofaunal assemblages from mud volcanoes in the Gulf of Cadiz: abundance, biodiversity and diversity partitioning across spatial scales, Biogeosciences, 10, 25532568, doi:10.5194/bg-10-2553-2013, 2013.

Decker, C., Morineaux, M., Van Gaever, S., Caprais, J.-C., Lichtschlag, A., Gauthier, O., Andersen, A. C., and Olu, K.: Habitat heterogeneity influences cold-seep macrofaunal communities within and among seeps along the Norwegian margin. Part 1: macrofaunal community structure, Mar. Ecol., 33, 205-230, 2011.

Eckelbarger, K. J. and Young, C. M.: Ultrastructure of the ovary and oogenesis in the methane-seep mollusc Bathynerita naticoidea (Gastropoda: Neritidae) from the Louisiana slope, Invertebr. Biol., 116, 299-312, 1997.

Etter, R. J. and Rex, M. A.: 1990 Population differentiation decreases with depth in deep-sea gastropods, Deep-Sea Res., 37, 1251-1261, 1990.

Etter, R. J., Rex, M. A., Chase, M. R., and Quattro, J. M.: Population differentiation decreases with depth in deep-sea bivalves, Evolution, 59, 1479-1491, 2005.
Foggo, A., Bilton, D. T., and Rundle, S. D.: Do developmental mode and dispersal shape abundance-occupancy relationships in marine macroinvertebrates?, J. Anim. Ecol., 76, 695-702, 2007.

Gaudron, S., Pradillon, F., Pailleret, M., Duperron, S., Le Bris, N., and Gaill, F.: Colonization of organic substrates deployed in deep-sea reducing habitats by symbiotic species and associated fauna, Mar. Environ. Res., 70, 1-12, 2010.

Geiger, D. L., Marshall, B. A., Ponder, W. F., Sasaki, T., and Warén, A.: Techniques for collecting, handling, preparing, storing and examining small molluscan specimens, Mollus. Res., 27, 1-50, 2007.

Govenar, B. and Fisher, C. R.: Experimental evidence of habitat provision by aggregations of Riftia pachyptila at hydrothermal vents on the East Pacific Rise, Mar. Ecol.-Evol. Persp., 28, 3-14, 2007.

Hart, M. and Marko, P.: It's about time: Divergence, demography, and the evolution of developmental modes in marine invertebrates, Integr. Comp. Biol., 50, 643-661, 2010.

Hodgson, A. N., Eckelbarger, K. J., and Young, C. M.; Sperm morphology and spermiogenesis in the methaneseep mollusc Bathynerita naticoidea (Gastropoda: Neritacea) from the Louisiana slope, Invertebr. Biol., 117, 199-207, 1998.

Jablonski, D. and Lutz, R. A.: Larval ecology of marine benthic invertebrates - Paleobiological implications, Biol. Rev. Camb. Philos., 58, 21-89, 1983.

Levin, L.: Ecology of cold seep sediments: interactions of fauna with flow, chemistry and microbes, Oceanogr. Mar. Biol. Ann. Rev., 43, 1-46, 2005.

Levin, L. A. and Sibuet, M.: Understanding continental margin biodiversity: A new imperative, Ann. Rev. Mar. Sci., 4, 79-112, 2012.

Levin, L. A., Mendoza, G. F., Gonzalez, J. P., Thurber, A. R., and Cordes, E. E.: Diversity of bathyal macrofauna on the northeastern Pacific margin: the influence of methane seeps and oxygen minimum zones, Mar. Ecol., 31, 94-110, 2009.

MacArthur, R. H. and Wilson, E. O.: The theory of island biogeography, Princeton University Press, Princeton, 1967.

Olu, K., Lance, S., Sibuet, M., Henry, P., Fiala-Médioni, A., and Dinet, A.: Cold seep communities as indicators of fluid expulsion patterns through mud volcanoes seaward of the Barbados accretionary prism, Deep-Sea Res. Pt. I, 44, 811-841, 1997.

Olu-Le Roy, K., Sibuet, M., Fiala-Médoni, A., Gofas, S., Salas, C., Mariotti, A., Foucher, J.-P., and Woodside, J.: Cold seep communities in the deep eastern Mediterranean Sea: composition, symbiosis and spatial distribution on mud volcanoes, Deep-Sea Res. Pt. I, 51, 1915-1936, 2004.

Pradillon, F., Shillito, B., Young, C. M., and Gaill, F.: Developmental arrest in vent worm embryos, Nature, 413, 698-699, 2001.

Quentel, E., Carton, X., and Gutscher, M.: Structure and temporal variability of Mediterranean Water in hydrological and marine seismic data South of Portimao Canyon (Gulf of Cadiz), from 1999 to 2002, International J. Geosciences, 2, 185-194, 2011.

Rex, M.: Community structure in the deep-sea benthos, Annu. Rev. Ecol. Syst., 12, 331-353, 1981.

Rex, M. A. and Warén, A.: Planktotrophic development in deep-sea prosobranch snails from the western North Atlantic, Deep-Sea Res., 29, 171-184, 1982.

Reynolds, K. C., Watanabe, H., Strong, E. E., Sasaki, T., Uematsu, K., Miyake, H., Kojima, S., Suzuki, Y., Fujikura, K., Kim, S., 
and Young, C.: New molluscan larval form: Brooding and development in a hydrothermal vent gastropod, Ifremeria nautilei (Provannidae), Biol. Bull., 219, 7-11, 2010.

Ritt, B., Desbruyères, D., Caprais, J., Gauthier, O., Ruffine, L., Buscail, R., Olu-Le Roy, K., and Sarrazin, J.: Seep communities from two mud volcanoes in the deep eastern Mediterranean Sea: faunal composition, spatial patterns and environmental control, Mar. Ecol.-Prog. Ser., 466, 93-119, 2012.

Rodrigues, C. F., Paterson, G. L. J., Cabrinovic, A., and Cunha, M. R.: Deep-sea ophiuroids (Echinodermata: Ophiuroidea: Ophiurida) from the Gulf of Cadiz (NE Atlantic), Zootaxa, 2754, 126, 2011.

Sasaki, T., Warén, A., Kano, Y., Okutani, T., and Fujikura, K.: Gastropods from Recent hot vents and cold seeps: systematics, diversity and life strategies, Topics in Geobiology, 33, 169-254, 2010.

Shilling, F. M. and Manahan, D. T.: Energy metabolism and aminoacid transport during early development of Antarctic and temperate echinoderms, Biol. Bull., 187, 398-407, 1994.

Swearer, S. E., Shima, J. S., Hellberg, M. E., Thorrold, S. R., Jones, G. P., Robertson, D. R., Morgan, S. G., Selkoem, K. A, Ruiz, G. M., and Warner, R. R.: Evidence of self-recruitment in demersal marine populations, Bull. Mar. Sci., 70, 251-271, 2002.

Ugland, K. I., Gray, J. S., and Ellingsen, K. E.: The speciesaccumulation curve and estimation of species richness, J. Anim. Ecol., 72, 888-897, 2003.
Vanreusel, A., Andersen, A., Boetius, A., Connelly, D., Cunha, M. R., Decker, C., Heeschen, K., Hilario, A., Kormas, K. A., Maignien, L., Olu, K., Pachiadaki, M., Ritt, B., Rodrigues, C., Sarrazin, J., Tyler, P., Van Gaever, S., and Vanneste, H.: Biodiversity of cold seep ecosystems along the European margins, Oceanography, 22, 118-135, 2009

Young, C. M.: Synchrony and sociality: breeding strategies in constant and variable environments, in: Aquatic life cycle strategies: survival in a variable environment, edited by: Whitfield, M., Matthews, J., and Reynolds, C., Marine Biological Association of the United Kingdom, Plymouth, 1-14, 1999.

Young, C. M.: Life histories, development and reproduction in the deep sea, in: Ecosystems of the world: The deep sea, Elsevier Science, edited by: Tyler, P. A., Amsterdam, 381-426, 2003.

Young, C. M.: Communities on deep-sea hard bottoms, in: arine hard bottom communities - Patterns dynamics diversity and change, edited by: Walh, M. M., Springer, Kiel, 39-60, 2009.

Young, C. M., He, R., Emlet, R. B., Li, Y., Qian, H., Arellano, S. M., Van Gaest, A., Bennett, K. C., Wolf, M., Smart, T. I., and Rice, M. E.: Dispersal of deep-sea larvae from the IntraAmerican Seas: Simulations of trajectories using ocean models, Integr. Comp. Biol., 52, 483-496, 2012. 